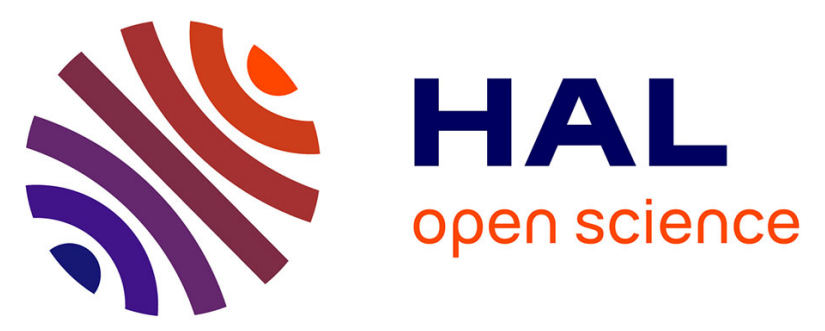

\title{
Improvement of the Containerized Logistics Performance Using the Unitary Traceability of Smart Logistics Units
}

Siraprapa Wattanakul, Sébastien Henry, Mohand Lounes Bentaha, Napaporn

Reeveerakul, Yacine Ouzrout

\section{- To cite this version:}

Siraprapa Wattanakul, Sébastien Henry, Mohand Lounes Bentaha, Napaporn Reeveerakul, Yacine Ouzrout. Improvement of the Containerized Logistics Performance Using the Unitary Traceability of Smart Logistics Units. 15th IFIP International Conference on Product Lifecycle Management (PLM 2018), Jul 2018, Turin, Italy. pp.410-419, 10.1007/978-3-030-01614-2_38 . hal-01963211

\section{HAL Id: hal-01963211 \\ https://hal.science/hal-01963211}

Submitted on 21 Mar 2019

HAL is a multi-disciplinary open access archive for the deposit and dissemination of scientific research documents, whether they are published or not. The documents may come from teaching and research institutions in France or abroad, or from public or private research centers.
L'archive ouverte pluridisciplinaire HAL, est destinée au dépôt et à la diffusion de documents scientifiques de niveau recherche, publiés ou non, émanant des établissements d'enseignement et de recherche français ou étrangers, des laboratoires publics ou privés. 


\title{
Improvement of the Containerized Logistics Performance using the Unitary Traceability of Smart Logistics Units
}

\author{
S. WATTANAKUL ${ }^{1 *}$, S. HENRY ${ }^{2}$, L. BENTAHA ${ }^{1}$, N. REEVEERAKUL ${ }^{3}$, and Y. \\ OUZROUT $^{1}$
}

\author{
${ }^{1}$ University of Lyon, University Lyon 2, DISP Laboratory, France. \\ ${ }^{2}$ University of Lyon, University Lyon 1, DISP Laboratory, France \\ ${ }^{3}$ College of Arts, Media and Technology, Chiang Mai University, Thailand \\ siraprapa.wattanakul@univ-lyon2.fr
}

\begin{abstract}
Based on the emergence of the Internet of Things, smart logistic units (container, pallet, cardboard) offers a new opportunity to improve the responsiveness to disturbances of the supply chain and to develop robust scheduling approach based on the knowledge extracted from the historical data of traceability on the smart logistic units. The limitations of the current traceability solutions are related in particular to the insufficient level of detail, the late availability of data and the scattering of data in databases of different actors in the supply chain who are reluctant to exchange them. Then, the unitary traceability based on the Internet of Things with a real-time tracking of multiple parameters of each object (position, temperature, vibration, humidity, etc.) is a solution which makes it possible to improve reactivity in real time when facing disturbances and to extract knowledge from historical data. Therefore, this paper proposes a conceptual framework based on seven activities that exploit smart container traceability data for real-time analysis and decision to monitor risks of disruptions and to mitigate the impact of disruptions.
\end{abstract}

Keywords: Supply Chain Performance, Smart Container, Unitary Traceability, Disruption Management, Reactivity

\section{Introduction}

Maritime shipping is the most significant mode of transport for international trading. Ships carry more than $80 \%$ of global trading volume. It reached 10.3 billion tons in 2016 . This amount values above $70 \%$ of total international trading values. Specifically, containerized transportation is the fastest growth, more than triple times in 20 years, from about 45 million TEUs (20-foot equivalent units) in 1996 to 140 million TEUs in 2017 [1]. A large number of containers are handled by container ships and ports. In each year since 2012, more than 600 million TEUs flows in and out ports around the world [2].

The containerized shipment is expected to operate under the just-in-time (JIT) production and the "Punctuality/Delivery in time" is a most critical factor [3]. For example, the case of container transhipment(s), the shipment has a limited time to transfer 
to the next scheduled vehicle. In a very competitive field where the service offered must be the most efficient (cost-time-sustainability), logistics operations are also planned in the JIT with very short of buffer time to minimize the costs on each operation. Thus, an unexpected disruption can influence the initial planning with very quickly consequences on the date of delivery. A single plan of the robust route (cost, time, sustainability) estimated under normal conditions is no longer the best solution. In an uncertain context consisting of disruptions, an additional solution which is invulnerable to disruptions and improves the operation performance such as the delivery time, the condition of product quality and cost becomes a supplementary approach.

Fig. 1. The uncertainty of operation

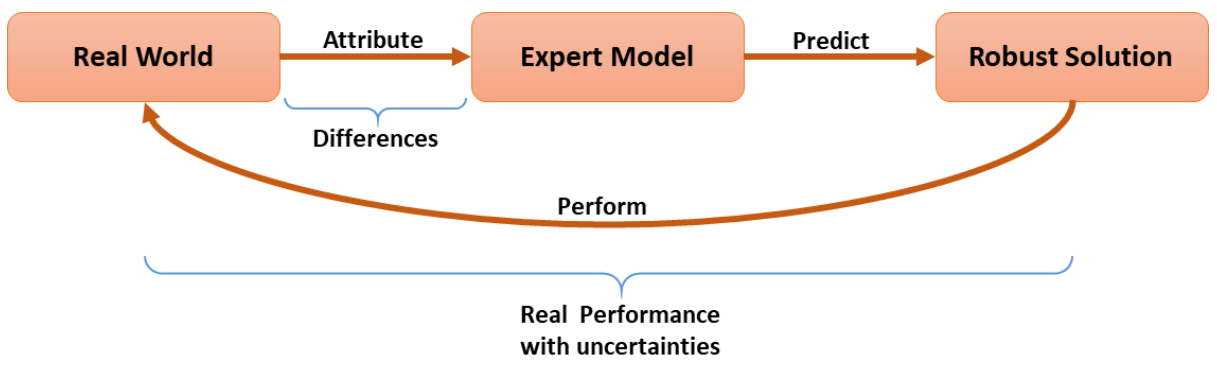

To be more specific, as illustrated in Fig. 1., an optimization of the operation planning is generally captured from the real world situation. Based on the historical data, some significant attributes of norm cases which represent the majority of situations are selected to construct the expert model. To support a decision, the expert model predicts and plans a robust solution. However, the expert model and the real world situation are different in some extent. While executing the plan, the operation may face a disruption and the performance declines from the expectation.

There are two approaches to improve the operation performance. First, to adjust the expert model by collecting feedback from the recent experienced operation to adjust the model [4]. This approach improves accuracy to the prediction. Still, not every scenario, in reality, can be included into the expert model. The operation takes risks on the uncertainty of operation performance. Another approach is to be proactive and reactive to disruptions in order to prevent and/or mitigate their impact. During the proactive period, the disruption is not yet critical to the performance. The operation monitors risk factors and raises awareness to prevent or to prepare for the incoming situation. In the other case of reactive approach, a disruption occurred and the operation performance is decreasing. The reactive approach analyses situation and suggests a method to minimize the impact $[5,6]$.

The emergence of the Internet of Things and in particular with smart logistics unit (container, pallet, cardboard) offers a new opportunity through a more precise and real-time monitoring of the logistics operation. These real-time sensing units allow visibility to explore the real operation and knowledge of disruptions. Later, the model of disruptions can further apply to their prediction, their detection and the assessment of their impact. 
The remainder of this paper is organized as follows: performance of the logistics chain and the performance measurement is discussed in Section 2. The uncertainty in the supply chain with its impact is presented in Section 3. Framework to integrate container traceability data to minimize the impact of disruption is described in Section 4. Finally, Section 5 summarizes our contributions and announces perspectives of this work.

\section{Performance of the Logistics Chain}

Generally, the logistics operation performance is measured in the view of process owner to identify the vulnerability in the chain. For the logistics chain, each function performance is measured by the operation cost, time and resource consumption [7]. A process modelling tool such as the SCOR model is used to point out the inefficient functions. The bottleneck functions or high-cost operations is then improved using these efficiency factors [8].

In the viewpoint of customer expectation, the service performance is rarely measured and clarified. Besides, the customer satisfaction to the container transport results in low to average in a survey of global shipper 2017 [17]. On each trip, operators concern costs, time and resource consumption of the operation while shippers expect differently in the package arrival time and its quality condition [9]. However, the current traceability system has a limitation in data accessibility of the package throughout the logistics chain. In consequence, the measurement of service performance is limited.

Fig. 2. The Current traceability system (EPCIS)

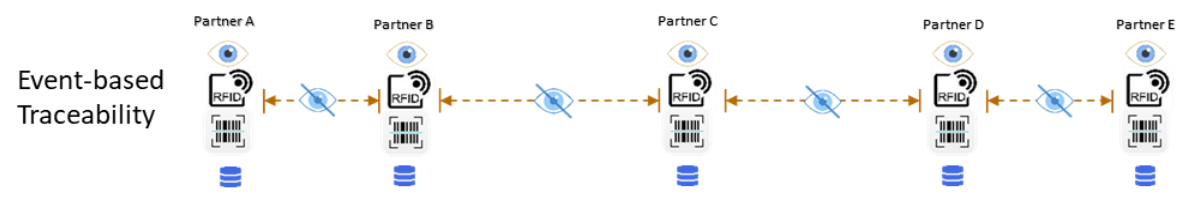

Current global traceability standard offered by GS1, each traceable unit is tracked and traced under the Electronic Product Code Information Services (EPCIS) as shown in Fig. 2. Each chain partner captures events of the tracing units (date-time, location, event-type e.g. departure, arrival, transfer). Data of the operation are scattered in partners' storages and the data sharing is in reluctance. Especially the data that can imply the performance $[3,10]$. Towards two major objectives of the transportation, a shipment should arrive safely and on-time, the existing traceability system limits the evaluation of the service performance regarding these objectives as follows: 


\subsection{Limitation in the product quality assurance}

The EPCIS tracks and traces the logistics units such as vehicle, container, pallet and carton. The traceability records the trajectory flow and events of each tracking items. The parameters related to the goods quality are not included. The environment or condition of the transportation storage is not maintained [11]. However, environment parameters such as temperature and humidity are essential to products which are sensitive to the time and condition such as perishable products. In extra to the GS1 traceability standard, the monitoring and controlling of storage condition should be cautious $[12,13,14]$.

Furthermore, in case of the product lost or damage in the supply chain with several partners, it is difficult to investigate the root cause due to the unavailability of supply chain information and the communication of the whole logistics is limited $[15,14]$.

\subsection{Limitation in the on-time shipment assurance}

Disruptions can initiate a delay to the shipment. Handling disruptions requires visibility of the operation through the logistics chain in real time. Then, the pattern of the normal operations and the operations with disruption can be distinguished. Risks and impact of disruptions should also be monitored in real time. Further, the decision time for disruption response is shortened and the disruption impact such as delay time can also be minimized. However, as mentioned, the supply chain visibility is currently limited by scattered traceability data storage.

Traceability data of the logistics operation seems to be a critical resource to evaluate the service performance in terms of the product quality surveillance and the delivery punctuation. Delay time is a significant factor that degrades the goods quality and the customer satisfaction [17].

\section{$3 \quad$ Uncertainty in Logistics}

\subsection{Disruptions}

Planning the logistics operation, the carrier considers routes and scheduling based on several factors in order to secure the plan and to minimize the operating costs. Factors such as the transportation network, route, vehicle, facility equipment and service operators are estimated on the consumption demand [18]. However, during the operation execution, disruptions can threaten the plan such as port congestion, accident, weather, tide condition, operator's mistake or even the consequence effect of the previous event. For example, the US West Coast labour dispute in February 2015 for a month affected the liner network globally for a year. From that time on the dispute, the liner delay had increased every five months and reached the highest average of delay at $38.3 \%$ in February 2016 [19]. Furthermore, the logistics operation time can be affected by more than one event. Currently, it is hard to distinguish and quantify the delay of February 2016 effected by the labour disputation, by the seasonal event of Chinese New Year or by any other disruptions. 


\subsection{Impact of disruptions}

Disruptions can directly impact customer expectations in terms of shipment delay, reduced product value, damaged or lost. Moreover, the negative impact also effects indirectly to the operation performance of partners. Not only the shipment carrier loses reliability from shippers. Nearly $90 \%$ of shipment stakeholder throughout the chain believes that a disruption is relevant to the loss of their reputation and their clients. Even the delay occurred previously in the chain by the other actors or any disruption, delays in delivery are frequently considered as a responsibility of the company that customer is dealing [20].

\section{A Conceptual Framework for Real-time Management}

According to the previous study proposed in [21], the technology of Smart Container $[22,23]$ offers the capturing of container status parameters through the operation seamlessly in real-time as shown in Fig.3. The operation of each container is recorded to the historical database. The situation awareness of containers enables the logistic chain analysis in all decision level (operational, tactical, strategical). This research aims to extend the ability of the smart container by improving the service performance of the container logistics operation in disruptions.

\subsection{Smart Container for Extended Real-time Traceability}

Fig. 3. The traceability system using the smart container

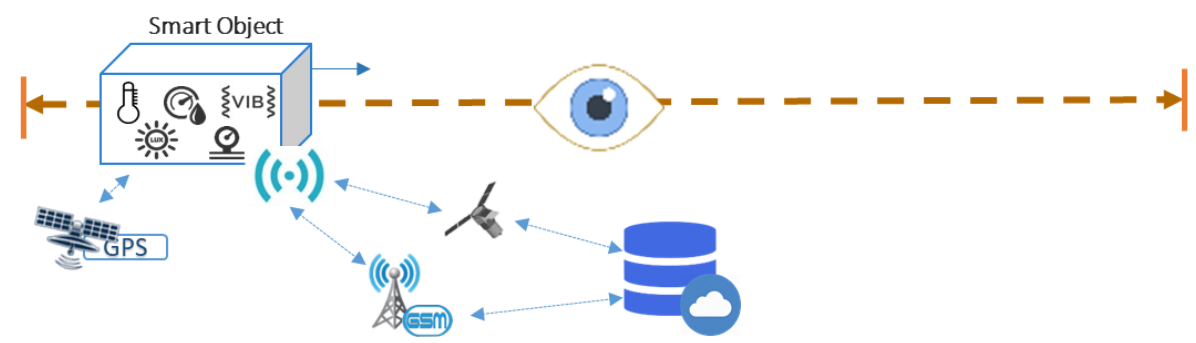

The traceability data of the smart container is capable to measure the service performance in the product quality assurance and the on-time shipment assurance. The parameters of temperature, humidity, vibration and door opening status enables the monitoring of the product quality by means of proper storage condition and storage safety. The parameter of GPS location can interpret the trajectory of the container and the time spent on each logistics leg. Then, the detection of anomaly determines the container movement pattern and the location of incident is specified. Furthermore, the surrounding environment such as weather and traffic can be observed and comprehended to the operation situation. The prediction of on-time shipment service can be proactive. 


\subsection{Performance improvement based on the smart container}

With the capability of the smart container, two strategies are proposed to improve service performance of the logistics operation.

\section{The 1st strategy - Finding the "robust" route.}

In order to identify the route for a container or a shipment from the route network offered by liners, each shipper or forwarder has a different preference. Based on an individual preference of shippers or forwarders, the "robust" route can be considered based on the criteria of the efficiency of the operation performance (cost, time, sustainability) and the robustness of the service performance (delay, goods quality):

- Cost - the logistics cost is a part of product capital cost. Minimizing the cost of shipment delivery benefits value to the business.

- Time - the supply chain concerns the planning of warehouse, production and time to market so the arrival time of material, parts or product affects to the plan and value of the product. The Estimated Time of Arrival (ETA) of shipment is included in the supply chain planning.

- Sustainability - logistics consume high volume of fuels and emits pollution. This raises the chance of higher cost in the future. Minimizing the emission on logistics trips becomes a highlight of shippers and carriers' interest [24].

- Robustness in delay -This criterion is to identify the route configuration with minimized chance and impact of the delay.

- Robustness in goods quality - a hazard treatment or the improper condition of the container storage can damage goods and its value. This criterion identifies the route that has least chance of the product quality lost from logistics.

These criteria are conflicted on one another. For example, choosing the cheapest route carrier, it may consume a long time of travelling with high emission rate and in the high risk of delay and product damage. Moreover, each shipper can have different interests and different acceptable range and weight balance on each. The shipment route selection then should be in multi-criteria to identify the route that is the most robust to the shipper preference. However, the information of the ETA and Sustainability criteria are based on the normal situation. It may not be true in real operation so shippers still have to take a risk on these criteria.

\section{The 2nd strategy - Being Proactive and Reactive to disturbances.}

In order to enhance the risk of the first strategy on the route planning, this strategy aims to improve the service performance of the operation when a disruption occurs, the traceability data raises situation awareness of each container as follows:

1. Being proactive by predicting and detecting disruptions - as the traceability data is captured in real-time. When a disruption occurred, the behaviour of data is changed differently from the normal operation pattern. The situation of the disruption is detected and becomes aware. The incoming shipments then predict the possibility of 
the disruption impact based on the container status, the disruption situation and the historical data.

2. Being reactive by diagnosis root causes of the disruption - based on the historical data of the containerized logistics with the extended situation information, the root cause should be identified to support the reactivity decision.

3. Being reactive by predicting the impact of disruption - in order to make a decision on the reactivity planning precisely, each container considers its delay time caused by the disruption.

4. Being reactive by making the operation decision in a short time - a decision is made to choose a reactivity that minimizes the disruption impact.

Conducting these two strategies can be performed under the following conceptual framework for the containerized logistics.

\subsection{Conceptual Framework for the containerized logistics}

Regarding the proposed strategies, this study proposes a conceptual framework intend to maximize the performance of the containerized operation and also raising the satisfactory of shippers. The framework is as shown in Fig. 4. There are seven major activites to handle though the lifecycle of containerized logistics operation including normal operation and under a disruption such as port congestion. Each container continuously monitors, analyses its own status and adjust its operation in a near real time.

Fig. 4. Conceptual Framework for the containerized logistics

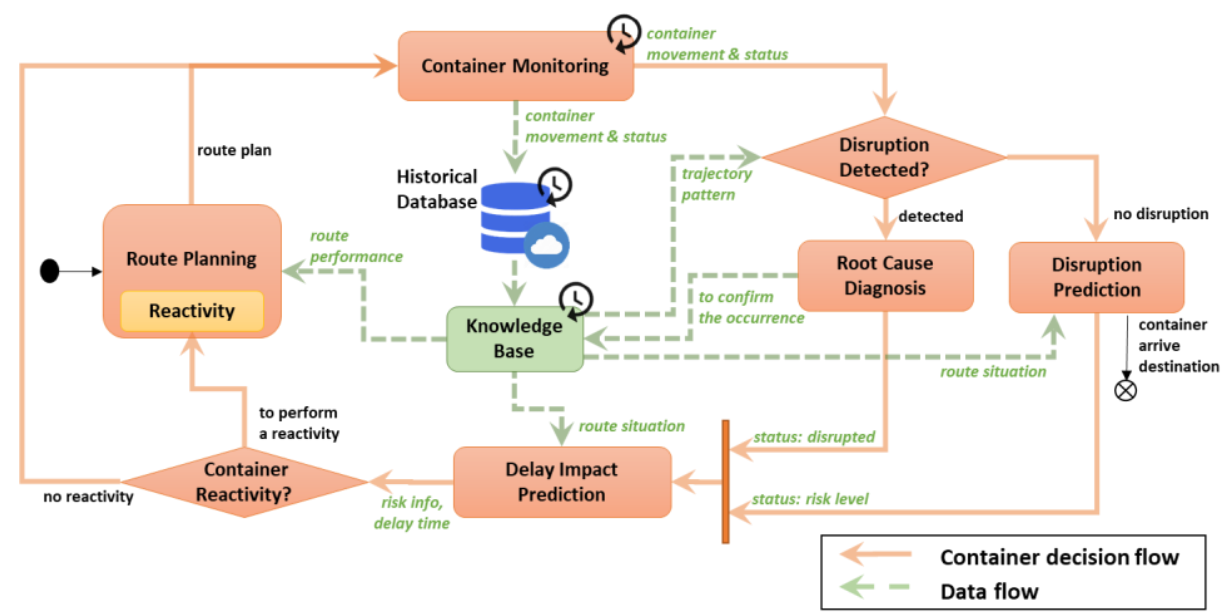

Once the container starts the logistics process as defined in its route plan ("Route Planning" by a tool of robust route planner e.g. Navigate). Each smart container seamlessly captures data parameters such as GPS location, temperature, humidity, vibrating rate and door opening in real time through the travel trip by the "Container Monitoring". These real-time container data are used to support the analysis of decision functions along the container decision flow. Also, all these raw data are stored in 
the central cloud as a historical database. The "Knowledge Base" uses the historical data to classify the trajectory patterns of smart containers by an artificial intelligent approach e.g. Bayesian Network. The recent movement of containers can then be compared with the classified pattern to distinguish the container in the normal operation from the operation with occurred disruption.

Based on the classified trajectory patterns and the others abnormal traceability data such as such as the fluctuation of vibration, the change of temperature or humidity level, the container operation can detect the disruption.

- In case of normal operation - the container proactively predicts the risk of encountering a disruption by considering its own situation and the route situation provided by the knowledge base. 'the container own situation' means to recent captured parameters e.g. position, trajectory, timestamp, etc. and 'the route situation' is clustered from the recent trajectory of containers on the same route to identify traffic and disruption status of the travelling route.

- In another case of confronting a disruption - e.g. accident or long waiting time. The root cause should be diagnosed to identify significant features that characterize the disruption. This may improve the classification of trajectory patterns to detect and predict the disruption in the future.

After that, based on the clustering of route situation and the historical of disrupted trajectory pattern, the total delay along the remaining travel trip is predicted for the container. Each container considers its predicted situation and expects to achieve as its robust plan, otherwise, it should execute a reactivity to adjust the operation process. Containers are able to communicate and making a deal on the reactivity e.g. operation sequencing. The process adjustment decision should fulfil the goal of containers robust plan while the operation productivity rate is not reduced. Repeatedly, smart containers are monitored and adapted until it reached the destination. The overall delay time of containers is expected to be reduced and the position of incidents can also be identified by this approach.

This conceptual framework intends to enhance the service performance from the customer view of the containerized logistics service as a major. However, the Knowledge Base contains information of the logistics network which can offers a support on decisions to the other viewpoints in logistics such as liners, shippers, freight forwarder and port operator.

\section{CONCLUSIONS}

In the maritime container industry, the customer satisfaction is in positive impressed. By chance of an uncertainty, disruptions can impact logistics in both the product quality and on-time delivery. This study focuses on improving the performance of the containerized logistics service. A conceptual framework for planning, monitoring and controlling the container shipment under the shipper's expectation is proposed based on two major strategies. First, shippers select a robust route based on their preference (route efficiency and service robustness). Second, each container is proactively monitored for disruptions and when facing a disruption, the reactive control persists the 
container flow in shipper's expectation. These activities are limited by the visibility of the logistics chain operation to monitor and analyse the operation situation, and also to make decisions on disturbance mitigation in a near real-time.

The emerging of smart container technology offers traceability data that improve visualization of the logistics operation. The availability of traceability data in container storage condition and its movement can extend the awareness to the logistics situation. Data are recorded in the central knowledge base. With seamless data visibility and quality, the improvement of logistics chain performance can be conducted using the proposed strategies.

The central knowledge base provides the classified trajectory patterns to support decisions in a near real time. Along the travelling, each smart container proactively perceives the situation of itself by using data provided by the knowledge base to predict the chance of confronting to disruption and the possible delay time. A reactivity may be required to adjust the operation process in order to improve the performance.

In the near future, the proposed framework will be simulated using AnyLogic to proof the concept. Elements such as the knowledge base, prediction models of disruption and delay impact will be developed.

\section{ACKNOWLEDGEMENT}

This work is supported under the Erasmus Mundus's SMARTLINK (South-east-west Mobility for Advanced Research, Learning, Innovation, Network and Knowledge).

\section{REFERENCES}

1. UNCTAD, The United Nations Conference on Trade and Development. (2017) The Review of Maritime Transport 2017 (UNCTAD/RMT/2017). New York and Geneva: United Nations Publication. http://unctad.org/en/PublicationsLibrary/rmt2017_en.pdf

2. The world bank (2017) Statistics of Container Port Traffic (TEU: 20 foot equivalent units). https://data.worldbank.org/indicator/IS.SHP.GOOD.TU

3. SEALS Consortium. (2008) Final Report: Statistical coverage and economic analysis of the logistics sector in the EU (SEALS) prepared for the European Commission, DG Energy and Transport. Technical Report. ProgTrans AG

4. Kridel D, Dolk D, Castillo D (2015) Adaptive Modeling for Real Time Analytics: The Case of" Big Data" in Mobile Advertising. In: System Sciences (HICSS), 48th Hawaii International Conference. IEEE, Hawaii, pp 887-896. doi:10.1109/HICSS.2015.111

5. Elluru S, Gupta H, Kaur H, Singh SP (2017) Proactive and reactive models for disaster resilient supply chain. Annals of Operations Research 1-26. doi:10.1007/s10479-017-2681-2

6. Chung SH, Tse YK, Choi TM (2015) Managing disruption risk in express logistics via proactive planning. Industrial Management \& Data Systems 115(8):81-1509. doi: 10.1108/IMDS-04-2015-0155

7. Verdouw CN, Wolfert J, Beulens AJM, Rialland A (2016) Virtualization of food supply chains with the internet of things. Journal of Food Engineering 176:128-136. doi: 10.1016/j.jfoodeng.2015.11.009 
8. Aboulaid H, Jardini B, Sedqui A, Elkayl M, Britel MR, Amri M, Lyahyaoui A (2016) Process re-engineering and success of integration projects of information technologies case study: Process modeling of a cross docking platform of a car manufacturer. In: 3rd Logistics Operations Management. IEEE, pp 1-6. doi:10.1109/GOL.2016.7731697

9. Balci G, Cetin IB, Tanyeri M (2018) Differentiation of container shipping services in Turkey. Transport Policy 61:26-35. doi: 10.1016/j.tranpol.2017.10.004

10. Fisseler D, Kemény Z, Reiners R (2016) Monitoring and control framework for business processes in ubiquitous environments. In: Ubiquitous Intelligence \& Computing, Advanced and Trusted Computing, Scalable Computing and Communications, Cloud and Big Data Computing, Internet of People, and Smart World Congress. IEEE, pp 863-868. doi: 10.1109/UIC-ATC-ScalCom-CBDCom-IoP-SmartWorld.2016.0136

11. GS1 AISBL (2016) EPC Information Services (EPCIS) Standard, Release 1.2. https://www.gs1.org/epcis

12. Wang J, Yue H (2017) Food safety pre-warning system based on data mining for a sustainable food supply chain. Food Control 73:223-229. doi:10.1016/j.foodcont.2016.09.048

13. Xiao X, Wang X, Zhang X, Chen E, Li J (2015) Effect of the quality property of table grapes in cold chain logistics-integrated WSN and AOW. Applied Sciences 5(4):747-760. doi:10.3390/app5040747

14. Kim WR, Aung MM, Chang YS, Makatsoris C (2015) Freshness Gauge based cold storage management: A method for adjusting temperature and humidity levels for food quality. Food control 47:510-519. doi:10.1016/j.foodcont.2014.07.051

15. Guo X, Wei D (2014) Under the Environment of Supply Chain Logistics Outsourcing Decision and Risk Research. In: International Conference on Logistics Engineering, Management and Computer Science. Atlantis Press, pp 168-171. doi:10.2991/lemcs-14.2014.39

16. Yuen KF, Thai V (2017) Barriers to supply chain integration in the maritime logistics industry. Maritime Economics \& Logistics 19(3):551-572. doi:10.1057/mel.2016.10

17. Drewry and ESC (2017) Satisfaction survey in container transport: Customers rate service quality of ocean carriers "poor to average". Drewry Supply Chain Advisors and European Shippers' Council, London and Brussels. https://www.drewry.co.uk/news/news/satisfactionsurvey-in-container-transport-customers-rate-service-quality-of-ocean-carriers-poor-toaverage

18. Meng Q, Wang S, Andersson H, Thun K (2013) Containership routing and scheduling in liner shipping: overview and future research directions. Transportation Science 48(2):265280. doi:10.1287/trsc.2013.0461

19. Drewry (2016) Service reliability falls to 12-month low. https://www.drewry.co.uk/news/ news/service-reliability-falls-to-12-month-low

20. Angel M, Salazar F (2013) Proposal for the Implementation of a Wireless Sensor Network System for Container Transportation. In: Proceedings of the Industrial and Systems Engineering Research Conference. IISE pp 2074-2083.

21. Wattanakul S, Henry S, Bentaha ML, Reeveerakul N, Ouzrout Y (2017) Improving Risk Management by Using Smart Containers for Real-time Traceability. In: 9th International Conference on Logistics and Transport: Supply Chain 4.0 Challenges and Prospects. ICLT pp 222-230. http://www.iclogisticstransport.org/uploads/files/ICLT2017 Full Papers.pdf

22. Traxens (2017) Traxens Technology. https://www.traxens.com/en/technology

23. Mersk (2016) Smart containers listen and talk. https:// www.maersk.com/stories/smartcontainers-listen-and-talk

24. Bask A, Rajahonka M, Laari S, Solakivi T, Töyli J, Ojala L (2018) Environmental sustainability in shipper-LSP relationships. Journal of Cleaner Production 172:2986-2998. doi: 10.1016/j.jclepro.2017.11.112 